\title{
Radionuclides in Nephrourology, Part 1: Radiopharmaceuticals, Quality Control, and Quantitative Indices
}

\author{
Andrew T. Taylor \\ Department of Radiology and Imaging Sciences, Emory University School of Medicine, Atlanta, Georgia
}

\begin{abstract}
Learning Objectives: On successful completion of this activity, participants should be able to describe (1) the advantages and limitations of the available radiopharmaceuticals for radionuclide renal scintigraphy; (2) quality control elements needed to optimize the study; (3) approaches to the measurements of renal function; and (4) recommended quantitative indices and their diagnostic applications.
\end{abstract}

Financial Disclosure: This review was partially supported by a grant from the National Institutes of Health (NIH/NIDDK R37 DK38842). Andrew T. Taylor is entitled to a share of the royalties for the use of QuantEM software for processing MAG3 renal scans, which was licensed by Emory University to GE Healthcare in 1993. He and his coworkers have subsequently developed in-house, noncommercial software that was used in this study and could affect their financial status. The terms of this arrangement have been reviewed and approved by Emory University in accordance with its conflict-of-interest policies. The author of this article has indicated no other relevant relationships that could be perceived as a real or apparent conflict of interest.

CME Credit: SNMMI is accredited by the Accreditation Council for Continuing Medical Education (ACCME) to sponsor continuing education for physicians. SNMMI designates each JNM continuing education article for a maximum of 2.0 AMA PRA Category 1 Credits. Physicians should claim only credit commensurate with the extent of their participation in the activity. For CE credit, participants can access this activity through the SNMMI Web site (http:// www.snmmi.org/ce online) through April 2017.

Radionuclide renal scintigraphy provides important functional data to assist in the diagnosis and management of patients with a variety of suspected genitourinary tract problems, but the procedures are underutilized. Maximizing the utility of the available studies (as well as the perception of utility by referring physicians) requires a clear understanding of the clinical question, attention to quality control, acquisition of the essential elements necessary to produce an informed interpretation, and production of a report that presents a coherent impression that specifically addresses the clinical question and is supported by data contained in the report. To help achieve these goals, part 1 of this review covers information that should be provided to the patient before the scan, describes the advantages and limitations of the available radiopharmaceuticals, discusses quality control elements needed to optimize the study, summarizes approaches to the measurements of renal function, and focuses on recommended quantitative indices and their diagnostic applications. Although the primary focus is the adult patient, aspects of the review also apply to the pediatric population.

Key Words: ${ }^{99 m T c-M A G 3 ; ~} 99 \mathrm{mTC}-\mathrm{DTPA}$; renal scintigraphy; clearance; renal function; effective renal plasma flow; glomerular filtration rate; relative function

J Nucl Med 2014; 55:608-615

DOI: 10.2967/jnumed.113.133447

$\mathbf{R}$ adionuclide renal scintigraphy provides important functional data to assist in the diagnosis and management of patients with a variety of suspected genitourinary tract problems; however, the examination is underutilized because referring physicians may

Received Jul. 9, 2013; revision accepted Dec. 23, 2013.

For correspondence or reprints contact: Andrew T. Taylor, Jr., Emory University Hospital, Division of Nuclear Medicine, 1364 Clifton Rd., NE, Atlanta, GA 30322

E-mail: ataylor@emory.edu

Published online Feb. 17, 2014.

COPYRIGHT (c) 2014 by the Society of Nuclear Medicine and Molecular Imaging, Inc. have an incomplete knowledge of the advantages and limitations of renal scintigraphy, may not know when or when not to order a study, and may fail to formulate a well-defined clinical question. Moreover, the clinical perception of the utility of renal scintigraphy can vary from institution to institution because of marked differences in scan quality despite the use of the same radiopharmaceutical, comparable equipment, and identical billing. Differences in scan quality are primarily related to differences in physician and technologist training and supervision. The nuclear medicine physician needs to make certain that the clinical question is clearly formulated, the scan is appropriate, and the imaging procedure incorporates the elements required to optimize the study and best answer the clinical question. To help address these goals, part 1 of this review focuses on the available radiopharmaceuticals, patient preparation, clearance measurements, and quantitative indices that aid in diagnosis. Part 2 will illustrate several pitfalls and address common clinical indications, including the evaluation of suspected obstruction and renovascular hypertension. The primary focus is the adult patient, but aspects of the review also apply to the pediatric population.

\section{RADIOPHARMACEUTICALS}

The radiopharmaceuticals generally available for assessment of renal function and anatomy can be grouped into 3 broad categories: those filtered by the glomerulus, those retained in the renal tubules via proximal tubule receptor-mediated endocytosis from the glomerular filtrate (1), and those primarily secreted by the renal tubules via the organic anion transporter $(1,2)$.

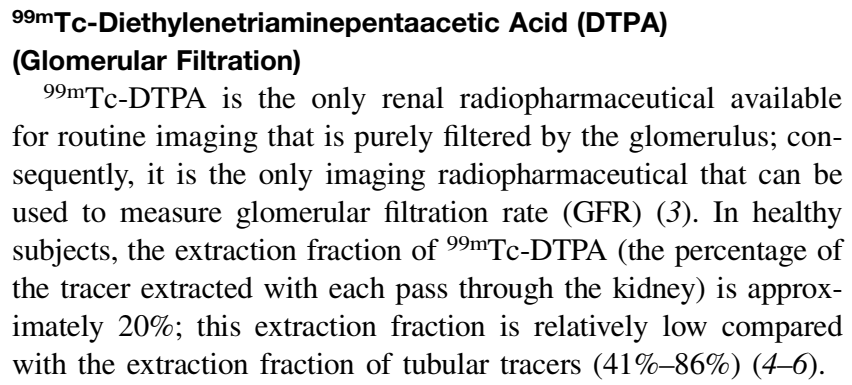


${ }^{51}$ Cr-Ethylenediaminetetraacetic Acid (EDTA)

(Glomerular Filtration)

${ }^{51} \mathrm{Cr}$-EDTA is a nonimaging radiopharmaceutical used to measure GFR via plasma sampling techniques; it is not available in the United States (3).

\section{I-Iothalamate (Glomerular Filtration)}

${ }^{125}$ I-iothalamate is used to measure GFR via plasma sampling techniques (3). ${ }^{125}$ I does not emit a photon of sufficient energy to be useful for renal imaging.

123I- and ${ }^{131}$ I-Orthoiodohippurate (OIH) (Tubular Secretion)

${ }^{123} \mathrm{I}$ - and ${ }^{131} \mathrm{I}-\mathrm{OIH}$ are cleared primarily by the proximal tubules although a small component is filtered by the glomeruli. The clearance of $\mathrm{OIH}$ is approximately $500-600 \mathrm{~mL} / \mathrm{min}$ in subjects with normal kidneys (4). ${ }^{131} \mathrm{I}$ - and ${ }^{123} \mathrm{I}-\mathrm{OIH}$ are no longer commercially available in the United States because of the introduction of ${ }^{99 \mathrm{~m}} \mathrm{Tc}$-mercaptoacetyltriglycine (MAG3), the poor imaging characteristics of ${ }^{131} \mathrm{I}$, the potential of ${ }^{131} \mathrm{I}-\mathrm{OIH}$ for delivering a high radiation dose, and the unfavorable logistics resulting from the relatively short half-life of ${ }^{123} \mathrm{I}(7,8)$.

\section{9mTc-MAG3 (Tubular Secretion)}

${ }^{99 m}$ Tc-MAG3 is highly protein-bound and is removed from the plasma primarily by the organic anion transporter 1 located on the basolateral membrane of the proximal renal tubules $(2,4,5) .{ }^{99 \mathrm{~m}} \mathrm{Tc}-$ MAG3 accumulates in the proximal tubular cell and is then transported into the tubular lumen via organic anion transporters on the apical membrane (9); if the apical membrane transporter is impaired to a greater extent than the basolateral transporter, ${ }^{99 \mathrm{~m}} \mathrm{Tc}-$ MAG3 can be extracted from the plasma with greater efficiency than it is transported to the tubular lumen, resulting in retained parenchymal activity. The extraction fraction of ${ }^{99 \mathrm{~m} T \mathrm{Tc}-M A G 3}$ is $40 \%-50 \%$ (5), more than twice that of ${ }^{99 \mathrm{~m} T c-D T P A}$. Because of its more efficient extraction, ${ }^{99 \mathrm{~m}} \mathrm{Tc}-\mathrm{MAG} 3$ is preferred over ${ }^{99 \mathrm{~m}} \mathrm{Tc}$-DTPA in patients with suspected obstruction and impaired renal function and is used in approximately $70 \%$ of the renal scans performed in the United States (10-15).

The clearances of ${ }^{131} \mathrm{I}-\mathrm{OIH}$ and ${ }^{99 \mathrm{~m}} \mathrm{Tc}-\mathrm{MAG} 3$ are often characterized as the effective renal plasma flow (4); however, there is a common misconception that the effective renal plasma flow (OIH clearance) is equivalent to renal plasma flow or, at least, proportional to renal plasma flow. The clearance of $\mathrm{OIH}$ and the clearance of ${ }^{99 \mathrm{~m}} \mathrm{Tc}$ tubular tracers from the plasma both require delivery to the kidney (renal plasma flow), but they also require extraction from the plasma. These parameters do not always change in a proportional fashion.

The ${ }^{99 m}$ Tc-MAG3 clearance, sometimes described as the tubular extraction rate, averages about $320 \mathrm{~mL} / \mathrm{min} / 1.73 \mathrm{~m}^{2}$ in adults under age $40 \mathrm{y}$ and decreases by approximately $1 \%$ per year after age 40 $\mathrm{y}(5,16,17)$. Although the clearance of ${ }^{99 \mathrm{~m} T c-M A G 3}$ is only $50 \%-$ $60 \%$ that of $\mathrm{OIH}$, the ${ }^{99 \mathrm{~m}} \mathrm{Tc}-\mathrm{MAG} 3$ clearance is highly correlated with the clearance of $\mathrm{OIH}$, and the ${ }^{99 \mathrm{~m}} \mathrm{Tc}-\mathrm{MAG} 3$ clearance can be used as an independent measure of renal function $(3,4)$. A small fraction of the administered dose of ${ }^{99 \mathrm{~m}} \mathrm{Tc}-\mathrm{MAG} 3$ is transported to the gut via the hepatobiliary system; this fraction increases in patients with impaired renal function (18). Occasionally, activity in the gallbladder has been mistaken for renal activity, and delayed images may show bowel accumulation (Fig. 1) (18-21).

\section{9mTC-L,L- and D,D-Ethylenedicysteine (EC)}

(Tubular Secretion)

${ }^{99 \mathrm{~m} T C-\mathrm{L}, \mathrm{L}-}$ and D,D-EC are enantiomers; both are excellent renal radiopharmaceuticals with clearances slightly higher than

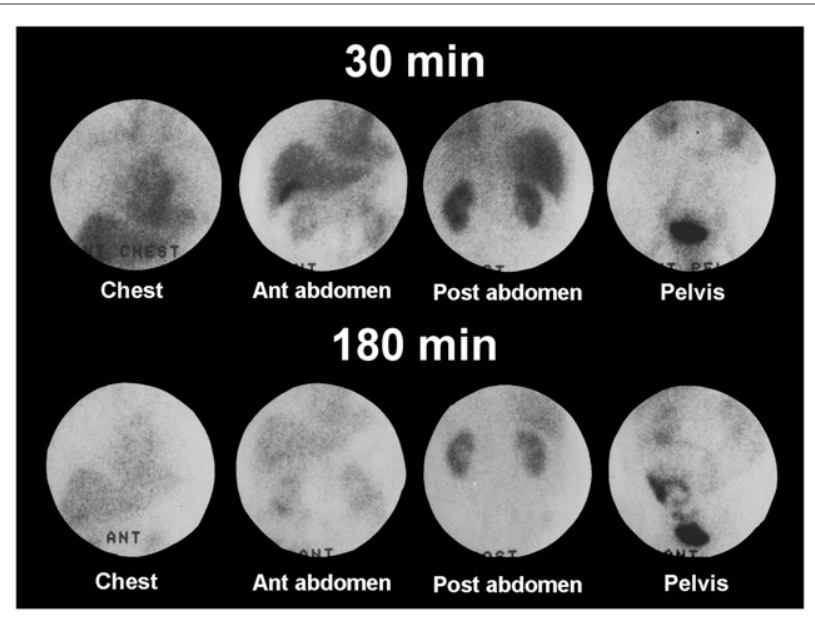

FIGURE 1. Images were obtained in patient with renal failure 30$45 \mathrm{~min}$ and 180-210 min after intravenous injection of 99mTc-MAG3. Activity can be seen in gallbladder on both early and late images, and bowel activity is clearly visualized on delayed images. Bowel activity on delayed images should not be confused with urine leak.

${ }^{99 m}$ Tc-MAG3 $(18,22)$. Although ${ }^{99 m}$ Tc-D,D-EC is cleared more rapidly than ${ }^{99 \mathrm{~m}} \mathrm{Tc}-\mathrm{L}, \mathrm{L}-\mathrm{EC}(23),{ }^{99 \mathrm{~m}} \mathrm{Tc}-\mathrm{L}, \mathrm{L}-\mathrm{EC}$ was first described and is available in several countries as a kit formulation.

\section{9m Tc- $\left(\mathrm{CO}_{3}\right)$ TricarbonyInitriloacetic Acid (NTA) (Tubular Secretion)}

Tc- $\left(\mathrm{CO}_{3}\right) \mathrm{NTA}$ is a new ${ }^{99 \mathrm{~m}} \mathrm{Tc}$ renal radiopharmaceutical with renogram curves and clearance equivalent to those of ${ }^{131} \mathrm{I}-\mathrm{OIH}$ (Fig. 2) (24,25). On the basis of its structure and charge distribution, ${ }^{99 \mathrm{~m} T c}-\left(\mathrm{CO}_{3}\right) \mathrm{NTA}$ is likely to be transported by the organic anion transporter 1. Unlike ${ }^{99 \mathrm{~m}} \mathrm{Tc}-\mathrm{MAG} 3$, however, preliminary studies in patients with chronic kidney disease show no evidence of gallbladder or gut activity $(18-21,25)$. At the time of writing $(2013),{ }^{99 m} \mathrm{Tc}-$ $\left(\mathrm{CO}_{3}\right)$ NTA is still under investigation and is not commercially available.

\section{9mTc-Dimercaptosuccinic Acid (DMSA) (Cortical Retention)}

99m Tc-DMSA is an excellent cortical imaging agent that is used primarily in pediatrics to evaluate relative function, pyelonephritis, and renal scarring $(26,27)$. Approximately $40 \%$ of the injected dose is retained by the renal tubules within $1 \mathrm{~h}$ after injection; the remainder is slowly excreted in the urine over the subsequent $24 \mathrm{~h}$. Recent data suggest that ${ }^{99 \mathrm{~m}} \mathrm{Tc}-\mathrm{DMSA}$ is initially bound to $\alpha 1$-microglobulin; the ${ }^{99 \mathrm{~m}}$ Tc-DMSA $\alpha 1$-microglobulin complex is then filtered by the glomerulus and accumulates in the kidneys via megalin/tubulin-mediated endocytosis from the glomerular filtrate (1). Consequently, the renal uptake of ${ }^{99 \mathrm{~m}} \mathrm{Tc}-\mathrm{DMSA}$ is dependent on renal blood flow, glomerular filtration, and proximal tubule receptor-mediated endocytosis.

\section{9mTc-Glucoheptonate (GH) (Cortical Retention and GFR)}

$99 \mathrm{~m} \mathrm{Tc}-\mathrm{GH}$ is cleared primarily by glomerular filtration, but approximately $10 \%-15 \%$ of the injected dose is retained in the renal tubules, allowing delayed, high-resolution static images to be obtained (28). ${ }^{99 \mathrm{~m}} \mathrm{Tc}-\mathrm{GH}$ tends to be used for static imaging if ${ }^{99 \mathrm{~m}} \mathrm{Tc}-$ DMSA is unavailable; because of the parenchymal retention, it should not be used for diuretic renography.

\section{Radiopharmaceuticals for Renal PET}

PET provides high spatial resolution, sensitivity, and quantitative accuracy. Several PET radiopharmaceuticals are available for 


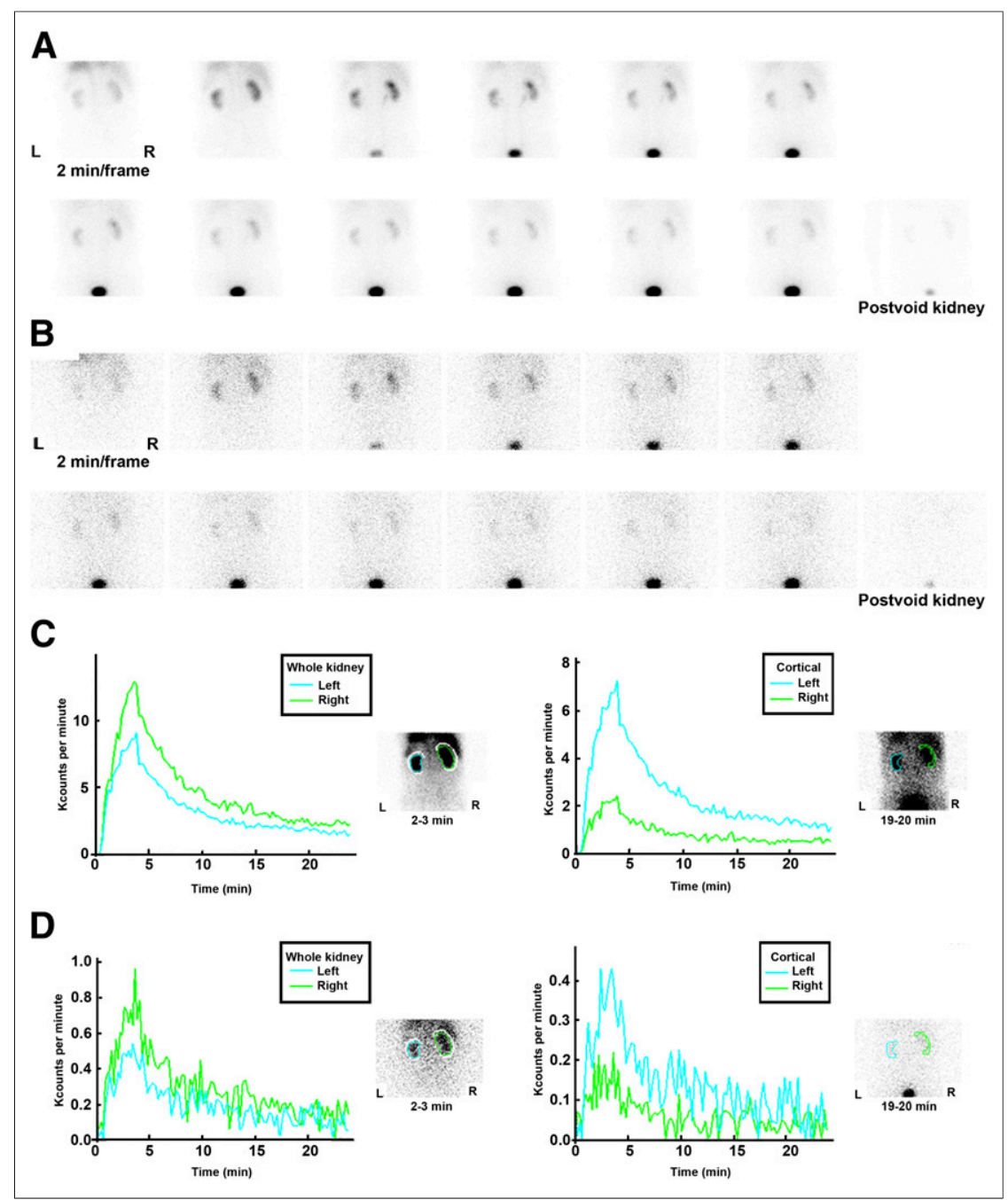

FIGURE 2. (A and B) Two-minute kidney images after simultaneous injection of $95.8 \mathrm{MBq}(2.59$ $\mathrm{mCi})$ of ${ }^{99 \mathrm{mTc}}(\mathrm{CO})_{3}(\mathrm{NTA})(\mathrm{A})$ and $11.8 \mathrm{MBq}(0.32 \mathrm{mCi})$ of ${ }^{131} \mathrm{I}-\mathrm{OIH}(\mathrm{B})$ in 74 -y-old man with stage 3 chronic kidney disease. ( $C$ and $D)$ Whole-kidney and cortical (parenchymal) renogram curves for $99 \mathrm{mTc}(\mathrm{CO})_{3}(\mathrm{NTA})(\mathrm{C})$ and for ${ }^{131} \mathrm{I}-\mathrm{OIH}$ (D). Renogram curves for ${ }^{131} \mathrm{I}-\mathrm{OIH}$ are quite noisy because of relatively low counting rate resulting from lower administered dose, poor capture of 364-keV photon of ${ }^{131}$ I by $9.5-\mathrm{mm}\left(3 / 8\right.$-in) crystal, and high-energy collimator not optimized for ${ }^{131}$. Difference in relative height of cortical curves in $C$ and $D$ is due to differences in size of relative cortical ROls. It is shape of cortical renogram curve that is important, not absolute height.

functional renal imaging; others are under development, but they are currently limited to research applications and were discussed in a previous review (29).

\section{GENERAL PATIENT PREPARATION AND INFORMATION}

Patients appreciate knowing what to expect when they are referred for an unfamiliar test. Information addressing the following topics should be provided to the patient before arrival.

\section{Procedure and Time Required for the Study}

The patient will receive an intravenous injection of the radiopharmaceutical and will lie quietly on an imaging table for 20-30 min. Depending on the protocol, there may be 2 imaging sessions.

\section{Hydration}

The patient should be told to arrive well hydrated and, in addition, to drink 2 large glasses of water just before arrival since good hydration minimizes the radiation dose to the bladder from the Auger electron of ${ }^{99 \mathrm{~m}} \mathrm{Tc}$ and facilitates interpretation of the examination.

\section{Diet and Medication}

Diclofenac, a nonsteroidal antiinflammatory drug, blocks the production of prostaglandins and has been shown to inhibit spontaneous ureteric contraction, prolong the transit time, and delay the time to peak height of the renogram curve of ${ }^{99 \mathrm{~m}} \mathrm{Tc}-$ MAG3 in healthy individuals (30-32). It is possible that other nonsteroidal antiinflammatory drugs may have a similar effect. Medication and dietary restriction for angiotensin-converting enzyme inhibition renography are discussed in part 2. For a basic renogram, there are no medication or dietary restrictions.

\section{Risk and Radiation Exposure}

Unlike radiographic contrast material, there is essentially no risk of an allergic or anaphylactic reaction. Depending on the radiopharmaceutical and the amount administered, the radiation exposure from a $37-$ to $370-\mathrm{MBq}$ (1-10 mCi) injection of ${ }^{99 \mathrm{~m}} \mathrm{Tc}-\mathrm{MAG} 3$ or ${ }^{99 \mathrm{~m}} \mathrm{Tc}-\mathrm{DTPA}$ ranges from $5 \%$ to $70 \%$ of the yearly background radiation from cosmic rays and naturally occurring radioactive sources in the environment (8); this exposure is less than $5 \%$ of the yearly radiation dose considered safe for doctors and technologists who work with radiation. In patients with normal kidney function, over $95 \%$ of the ${ }^{99 m}$ Tc-MAG3 leaves the body by $3 \mathrm{~h}$ (33). Patients can go to public places and use a bathroom without risk to others.

\section{Pregnancy}

If the patient is pregnant or thinks she may be pregnant, she should discuss this possibility with the nuclear medicine physician before arrival for the test.

\section{PROCEDURE}

\section{Voiding Before the Study}

The patient should void immediately before the study. This practice will lessen the possibility that the patient needs to void during the acquisition and is essential for diuretic studies since a full bladder may delay upper tract emptying.

\section{Administered Dose and Acquisition Parameters}

Renal scans are frequently performed after the intravenous injection of approximately $370 \mathrm{MBq}(10 \mathrm{mCi})$ of ${ }^{99 \mathrm{~m}} \mathrm{Tc}-\mathrm{MAG} 3$ or ${ }^{99 m}$ Tc-DTPA. Administration of activities in the range of $370 \mathrm{MBq}$ may be required to obtain sufficient counts to visualize the initial bolus as it transits the aorta and kidneys or to calculate quantitative flow indices (34-36); however, except for the evaluation of 
renal transplants, neither 2-s flow images nor quantitative flow calculations obtained in the first few seconds after injection have been clearly demonstrated to contribute to the evaluation of relative function, suspected obstruction, or renovascular hypertension (34-36). An administered dose of $370 \mathrm{MBq}$ is unnecessarily high for almost all applications, and a range from 37 to $185 \mathrm{MBq}$ is much more appropriate $(3,12,37-41)$.

Images are acquired dynamically for $20-30 \mathrm{~min}$ in 10 - to 20 -s frames and are usually displayed at 1- or 2-min intervals as the radioactive tracer is removed from the blood, transits the kidney, and enters the bladder. Postvoid views of the kidneys and bladder are recommended at the conclusion of the study (38).

\section{Dose Injection and Extravasation}

A poor bolus due to extravasation or venous obstruction can lead to inaccurate camera-based clearance measurements and result in an abnormal study with delayed uptake and washout. Injection into a limb with venous obstruction should be avoided; positioning the arm at a $90^{\circ}$ angle to the body will minimize the likelihood of axillary retention of the tracer. A short 30- to 60-s image over the injection site at the conclusion of the study is a useful and recommended quality control procedure $(37,38)$. The degree of extravasation or infiltration can be estimated by dividing the counts/min at the site of infiltration by the counts/min injected.

\section{Whole Kidney Versus Cortical (Parenchymal) Regions of Interest (ROIs)}

Time-activity curves are generated after placement of an ROI over each kidney, the renal cortex (parenchyma), or retained activity in the collecting system (Fig. 3). Data are recorded on the computer for subsequent analysis. The whole-kidney ROI consists of an ROI placed around the entire kidney, including the renal pelvis. Quantitative values generated using this ROI will be affected by retention of tracer in both the kidney parenchyma and the renal pelvis. Tracer retention may occur in pathologic states such as diabetic nephropathy or obstruction but may also occur in nonpathologic states such as a nonobstructed dilated collecting system or mild dehydration. To obtain a better assessment of parenchymal function, ROIs can be restricted to the renal cortex (parenchyma), excluding any retained activity in the renal pelvis or calyces.

\section{Patient Position}

Imaging is usually performed with the patient supine. The supine position allows a more accurate estimate of relative renal function since the kidneys are more likely to lie at the same depth (42). Nephroptosis has been observed in $22 \%$ of kidneys when patients are imaged in a seated position (43). A change in kidney position due to nephroptosis can lead to a difference in the measurement of relative uptake due to differences in attenuation rather than differences in relative function.

\section{Background Correction}

Background consists of radiotracer present in blood and the interstitial space of the kidney as well as in the tissues anterior and posterior to the kidney. For tracers with a low extraction fraction such as ${ }^{99 \mathrm{~m} T c-D T P A}$, the background counts during the second to third minute after injection can be as high as $50 \%-80 \%$ of the total activity in the renal ROI (37). To correct for these nonrenal counts present in the renal ROI, background correction needs to be performed. For the calculation of relative renal uptake, a perirenal background (Fig. 2C) normalized to the kidney ROI is preferred over background regions placed inferior to the kidney $(37,44)$;
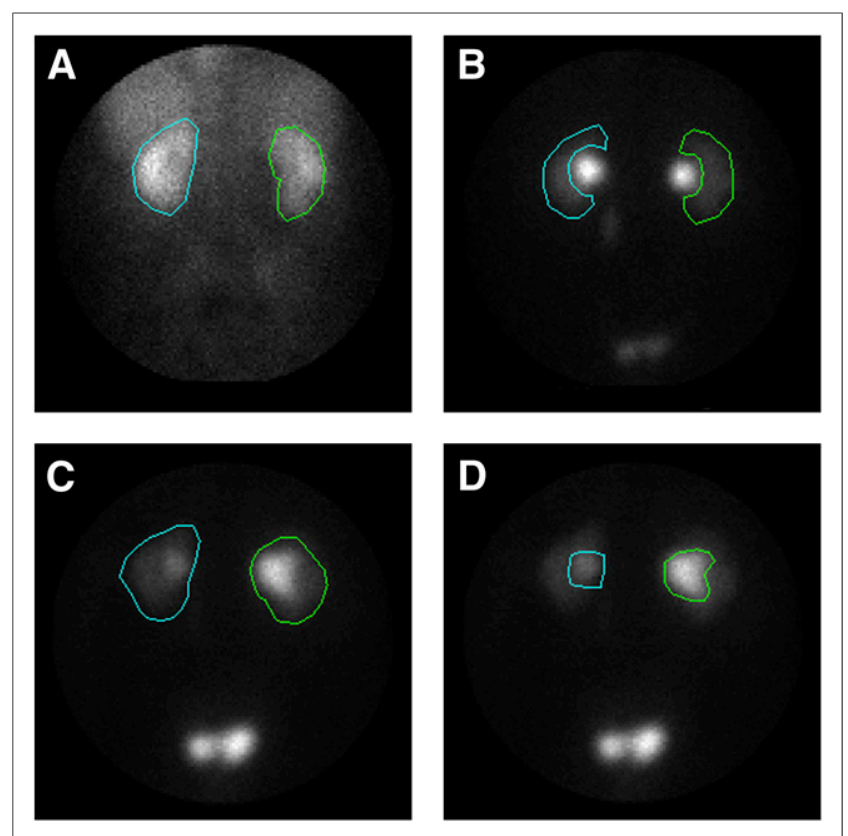

FIGURE 3. Whole-kidney, cortical, and collecting system ROls are illustrated on images from baseline and postfurosemide 99mTc-MAG3 scans. (A) Whole-kidney ROI is illustrated on image obtained 2-3 min after injection. (B) Parenchymal (cortical) ROls were assigned using 19- to 20-min image to ensure that parenchymal ROI excludes collecting system; assigning parenchymal $\mathrm{ROI}$ on 2- to 3-min image is problematic because collecting system is not visualized on this image. (C) Whole-kidney ROI was assigned using 1- to 2-min image after furosemide injection (2-stage diuretic acquisition protocol). (D) Collecting system ROI was assigned using 1- to 2-min image after furosemide injection. (Reprinted with permission of (50).)

automated background assignments that track the kidney ROI reduce processing time and enhance reproducibility. If the background region includes tracer that subsequently accumulates in the renal pelvis, background may be over-subtracted in the latter part of the study, leading to errors in generating quantitative parameters such as the 20-min/maximum count ratio. Further details regarding background correction methods and quality control of quantitative measurements of renal function obtained from the renogram are available in an ISCORN consensus report (37).

\section{Time-Activity (Renogram) Curves}

Whole kidney and cortical (parenchymal) time-activity curves are illustrated in Figure 2; the difference in the relative height of the cortical curves is due to the differences in the size of the relative cortical ROIs. The function of the cortical curve is to display the transit time through the cortex without contaminating the curve from activity in the collecting system; the cortical (parenchymal) ROIs are not drawn to have equal areas but to exclude the renal pelvis (45). Unless the cortical counts are normalized for area, a cortical ROI with a larger area will have more counts than a contralateral cortical ROI with a smaller area; consequently, the renogram curve with the larger cortical ROI will have a greater maximum. It is the shape of the cortical renogram curve that is important, not the absolute height. It is important to note that parameters generated from the cortical renogram curves may be spurious because of patient motion; parameters generated from cortical curves derived from poorly functioning kidneys may also be spurious because of low counts and noise. 


\section{Patients with a Percutaneous Nephrostomy or Neobladder}

When a patient presents with a percutaneous nephrostomy, the nuclear medicine physician needs to decide whether to clamp the nephrostomy. This decision depends on the clinical question to be answered and may require consultation with the referring urologist. If possible, a neobladder with cutaneous drainage should be catheterized before the study to minimize reflux. Both of these issues will be discussed in more detail in part 2 .

\section{QUANTITATIVE INDICES}

\section{Relative Perfusion}

Renal perfusion is evaluated by the visual or quantitative analysis of the initial bolus as it transits the abdominal aorta and enters the renal arteries. With the exception of renal transplant evaluation, quantitative measurements of renal perfusion have not been demonstrated to contribute to renal scan interpretation and can be omitted (See "Administered Dose and Acquisition Parameters" [above] and "Areas for Future Research" [part 2]) (34-38).

\section{Relative Function}

The relative uptake of the radiopharmaceutical provides a measure of differential renal function (the specific function depends on the radiopharmaceutical) and should be reported. For ${ }^{99 \mathrm{~m}} \mathrm{Tc}-$ MAG3 and DTPA, the measurement is usually made by placing an ROI over each kidney and measuring the integral of the counts in renal ROI during the 1- to 2-, 1- to 2.5-, or 2- to 3-min period after injection or using the Rutland-Patlak plot (37). In subjects with normal renal function, the $95 \%$ confidence interval for the relative uptake of $99 \mathrm{~m}$ Tc-MAG3 using a perirenal background correction ranges from $42 \%$ to $58 \%$ (16). With the integral approach, the measurement needs to be made before any tracer is eliminated by either kidney. In patients with bilaterally impaired function and delayed excretion, the kidney-to-background ratio will be reduced compared with normally functioning kidneys; in this setting, the differential function measurement will be more accurate if the measurement is obtained not during the 1- to 3-min postinjection period but rather in the 1-min period just before any tracer leaves the kidney ROI (46).

\section{Renal Size}

Knowledge of renal size can assist in the interpretation of ${ }^{99 \mathrm{~m}} \mathrm{Tc}-$ MAG3 renal scans. Several chronic renal diseases will result in bilaterally small kidneys, whereas the kidneys may be bilaterally enlarged in early diabetic renal disease, acute interstitial nephritis, HIV nephropathy, and amyloidosis. A unilaterally small kidney is obvious, but a small kidney may not be obvious on a ${ }^{99 m}$ Tc-MAG3 renal scan when the contralateral kidney is similarly reduced in size; conversely, an abnormal increase in renal size may not be recognized if both kidneys are similarly enlarged but have a normal configuration. Correlative imaging studies may provide size information, but unpublished results from our institution indicate that approximately $50 \%$ of patients referred for renal scintigraphy lack prior imaging studies; moreover, even when reports are available, there is often no comment regarding renal size. Renal size (length in $\mathrm{cm}$ and area in $\mathrm{cm}^{2}$ ) can be determined from the pixel length and area of the whole-kidney ROI. Regression equations to define the upper and lower limits of renal size normalized for body surface area have recently been developed for adults (47). Routine measurement of renal size at the time of the ${ }^{99 m}$ Tc-MAG3 scan may assist in the detection of unsuspected bilateral increases or decreases in renal size and facilitate scan interpretation.

\section{Time to Peak, or Tmax}

The time to peak, or Tmax, simply refers to the time from radiopharmaceutical injection to the peak height of the renogram curve. 99mTc-MAG3 and ${ }^{99 m}$ Tc-DTPA renograms normally peak by 5 min and decline to half-peak height by $15 \mathrm{~min}$ after injection; however, physiologic retention of the tracer in the renal calyces or pelvis can alter the shape of the whole-kidney renogram curve in normal kidneys and lead to prolonged values for the time to peak, 20-min/ maximum count ratio, and $\mathrm{T}^{1} \frac{1}{2}$.

\section{The $T^{1} 1 / 2$}

The $\mathrm{T}^{1} / 2$ refers to the time it takes for the activity in the kidney to fall to $50 \%$ of its maximum value. The use of this value in scan interpretation will be discussed in part 2 .

\section{Postvoid Kidney Counts/Maximum or 1- to 2-Minute Kidney Counts}

Drainage from the renal pelvis can be facilitated by maximizing the pressure differential between the renal pelvis and bladder and by gravity. Requiring the patient to assume an upright posture for a few minutes and empty the bladder maximizes the pressure differential between the renal pelvis and bladder and allows gravity to facilitate urine drainage. Simple ratios that incorporate gravityfacilitated drainage from the kidneys such as counts in the postvoid kidney divided by the maximum counts in the kidney or counts in the postvoid kidney divided by counts at 1-2 min (normalized residual activity) appear to provide more robust measurements of drainage than the $\mathrm{T}^{1} \frac{1}{2}(38,48-51)$.

\section{0-Min/Maximum Count Ratio}

The 20-min/maximum count ratio is the ratio of the kidney counts at $20 \mathrm{~min}$ to the maximum (peak) counts; this measurement provides an index of the transit time and parenchymal function and is often obtained for both whole kidney and cortical (parenchymal) ROIs. For ${ }^{99 m} \mathrm{Tc}-\mathrm{MAG} 3$, the normal 20 -min/maximum count ratio for cortical ROIs averages 0.19 , with SDs of 0.07 and 0.04 for the right and left kidneys, respectively (16). If the patient is not dehydrated and the 20-min/maximum count ratio for the cortical ROI exceeds 0.35 (greater than 2-3 SDs above the mean), the kidney is likely to be abnormal. In addition to detecting abnormal function, the 20-min/maximum and 20-min/1- to 2-min count ratios can be useful in monitoring patients with suspected urinary tract obstruction and renovascular hypertension $(39,40,48,52)$.

\section{Residual Urine Volume}

Residual urine volume can be measured on the basis of the counts in pre- and postvoid ROIs over the bladder and a measurement of the voided volume (53). This measurement assumes a constant postvoid volume and is relatively easy to perform; it is routine at some institutions and may detect unsuspected urinary retention. To maintain a consistent geometry, pre- and postvoid images should be obtained with the patient in the same position. The main source of error is tracer in the renal pelvis that drains into the bladder after the patient voids; when possible, patients should walk around for several minutes to facilitate and complete gravity-assisted drainage before voiding and obtaining the postvoid image.

\section{Urine Flow Rate}

The rate of urine flow can be useful in assessing the adequacy of diuresis after furosemide administration and can be calculated by dividing the voided volume at the conclusion of the study by the interval between the time of voiding before the study and time of voiding at the conclusion of the study. 


\section{Clearance Measurements}

The most common measure of renal function in clinical practice is serum creatinine; however, serum creatinine is affected by several factors (muscle mass, diet, age, certain drugs, illness, tubular secretion), and there is a wide range of serum creatinine values for all levels of GFR (54). Measurement of creatinine clearance using a 24-h urine collection is cumbersome, inconvenient, and often unreliable; moreover, repeated measurements in stable patients have shown a disappointingly high $25 \%$ coefficient of variation (SD/mean) $(54,55)$. The initial evaluation of renal function can be improved using the 4-variable, Modification of Diet in Renal Disease study equation (56). Even with this equation, however, $20 \%-30 \%$ of subjects have an estimated GFR outside the relatively large $30 \%$ (70\%-130\%) accuracy range of the measured GFR (57-59). A more accurate measurement of renal function may be needed in patients at the extremes of age and body mass; in patients with severe malnutrition, grossly abnormal muscle mass (amputation, paralysis), high or low intakes of creatinine or creatine (vegetarian diet, dietary supplements), rapidly changing renal function; and in patients before kidney donation and before dosing with high-toxicity drugs excreted by the kidney. Measurement of renal function at the time of the scan can aid in the interpretation of a radionuclide study, provide a measurement of renal function independent of the estimated GFR, and serve as a baseline for monitoring changes. The 2 most widely used radionuclide techniques for evaluating renal function are plasma sample and camera-based clearance measurements.

\section{Plasma Sample Clearances}

The gold standard for measuring renal clearances involves timed urine collections after a constant infusion technique to maintain the plasma concentration of the tracer at a constant level (3). A variant of this technique uses a subcutaneous injection; however, both these methods are cumbersome, time-consuming, expensive, and limited to research applications. An alternative approach substitutes the plasma clearance for the renal clearance and avoids the necessity for urine collections. The plasma clearance is typically obtained using the single-injection, 2-compartment model of the plasma disappearance curve (60). The plasma disappearance curve can be characterized by multiple blood samples obtained over $90 \mathrm{~min}$ for tubular tracers but requires a longer time for GFR tracers because of their slower clearance $(3,61,62)$.

Simplified techniques based on 1 or 2 plasma samples have been developed to estimate the multisample clearance (3). The ${ }^{99 \mathrm{~m}} \mathrm{Tc}-$ MAG3 clearance can be estimated from the dose injected and the amount of radioactivity in a single blood sample obtained approximately $45 \mathrm{~min}$ after injection $(3,17,61)$, and the GFR can be estimated from the dose injected and the activity in 1 or 2 plasma samples obtained $1-4 \mathrm{~h}$ after injection $(3,62)$. These techniques generally provide reliable results, can be performed at the time of a standard renal scan using ${ }^{99 \mathrm{~m}} \mathrm{Tc}-\mathrm{MAG} 3$ or ${ }^{99 \mathrm{~m}} \mathrm{Tc}-\mathrm{DTPA}$, and allow chemotherapy to be optimized to an individual patient's underlying renal function (62).

Plasma sampling techniques have several sources of error. They assume a normal volume of distribution; if a patient has ascites, marked edema, or a large effusion, the tracer can diffuse into these extra fluid spaces and plasma clearance will not provide an accurate measure of renal clearance. Plasma sample clearances require meticulous technique and attention to detail. If the measurement is performed by a poorly trained or inexperienced individual, technical errors are easy to make and the results will be spurious. Because of the need for specialized training, extra effort, the necessity of handling plasma samples, and lack of reimbursement, plasma sample clearances are rarely available in the United States.

\section{Camera-Based Clearances}

Camera clearance methods that do not require blood or urine samples have been developed for ${ }^{13 \mathrm{I}} \mathrm{I}-\mathrm{OIH},{ }^{99 \mathrm{~m}} \mathrm{Tc}-\mathrm{DTPA}$, and ${ }^{99 \mathrm{~m}} \mathrm{Tc}-$ MAG3 (63-67). The principle is based on the fact that the initial tracer accumulation by the kidneys is proportional to the renal clearance. Camera-based techniques determine the tracer accumulation (counts) in the kidneys at a defined period shortly after injection and divide by the counts injected to obtain a percentage injected dose in the kidneys. The percentage injected dose is converted to a clearance measurement using a validated nomogram (67). Camera-based clearances appear to be reproducible and are superior to creatinine clearance for monitoring changes in renal function (68). Although camera-based clearances are considered to be less accurate than plasma sample clearances (3), they avoid sources of error (timing of plasma samples, correction for radioactive decay, dilution of standards, pipetting small volumes) inherent in plasma sample techniques.

Camera-based clearance measurements, however, have their own sources of error. To obtain the percentage injected dose in each kidney, kidney counts have to be corrected for background, infiltration, attenuation, and renal depth. Two common sources of error are background subtraction and the estimation of renal depth. Since ${ }^{99 \mathrm{~m}}$ Tc-MAG3 is extracted more than twice as efficiently as ${ }^{99 \mathrm{~m}} \mathrm{Tc}-$ DTPA, the kidney-to-background ratio will be much higher for ${ }^{99 \mathrm{~m}}$ Tc-MAG3 than ${ }^{99 \mathrm{~m}}$ Tc-DTPA and any potential error introduced by background subtraction will be reduced.

Renal depth is usually estimated from a nomogram based on height and weight $(42,69)$. To the degree that a population-derived nomogram fails to fit a particular individual, the clearance measurement will vary from the true clearance. The sources of error due to background, self-attenuation, and renal depth tend to be reflected in a wider confidence interval associated with the accuracy of camerabased clearance compared with plasma sample clearances; however, in adult patients, these parameters tend to be constant in sequential studies and have less effect on reproducibility. Commercial camerabased techniques are currently available for measuring GFR $\left({ }^{99 \mathrm{~m}} \mathrm{Tc}-\right.$ DTPA), effective renal plasma flow $\left({ }^{131} \mathrm{I}-\mathrm{OIH}\right)$, and the ${ }^{99 \mathrm{~m}} \mathrm{Tc}-\mathrm{MAG} 3$ clearance. In evaluating the reliability of commercial software, it is important to confirm that the vendor has incorporated the appropriate quality control features and provided citable validation studies to confirm that the software is performing as claimed. Preliminary results suggest that the accuracy of $\gamma$-camera clearance methods can be improved using software adapted to a dualacquisition protocol (70).

\section{CONCLUSION}

Radionuclide renography can be a complex subject since several radiopharmaceuticals are available to image the kidney and monitor renal function; multiple quantitative indices can be generated, and protocols vary depending on institutional preference and clinical setting. Part 1 of this review has focused on the advantages and limitations of available radiopharmaceuticals, the quality control elements needed to optimize the study, and measurement of common quantitative indices designed to assist in scan interpretation. Part 2 will use the information presented in part 1 to focus on specific diagnostic applications, including suspected obstruction and renovascular hypertension. Potential pitfalls are included in both 
part 1 and part 2 and in a series of SAM questions designed to supplement and highlight important procedural elements and aspects of scan interpretation.

\section{REFERENCES}

1. Weyer K, Nielsen R, Petersen SV, Christensen EI, Rehling M, Birn H. Renal uptake of ${ }^{99 \mathrm{~m}} \mathrm{Tc}$-dimercaptosuccinic acid is dependent on normal proximal tubule receptor-mediated endocytosis. J Nucl Med. 2013;54:159-165.

2. Shikano N, Kanai Y, Kawai K, Ishikawa N, Endou H. Transport of ${ }^{99 m}{ }^{9} c-M_{A G}$ via rat renal organic anion transporter 1. J Nucl Med. 2004;45:80-85.

3. Blaufox MD, Aurell M, Bubeck B, et al. Report of the Radionuclides in Nephrourology Committee on renal clearance. J Nucl Med. 1996;37:1883-1890.

4. Eshima D, Taylor A Jr. Technetium- $99 \mathrm{~m}\left({ }^{99 \mathrm{~m} T c)}\right.$ mercaptoacetyltriglycine: update on the new ${ }^{99 m}$ Tc renal tubular function agent. Semin Nucl Med. 1992;22: 61-73.

5. Bubeck B, Brandau W, Weber E, Kälble T, Parekh N, Georgi P. Pharmacokinetics of technetium-99m-MAG3 in humans. J Nucl Med. 1990;31:1285-1293.

6. Schaap GH, Alferink TH, de Jong RB, Oe PL, Roos JC, Donker AJ. ${ }^{99 m}$ Tc$\mathrm{MAG}_{3}$ : dynamic studies in patients with renal disease. Eur J Nucl Med. 1988;14: 28-31.

7. Marcus CS, Kuperus JH. Pediatric renal I-123 orthoiodohippurate dosimetry. J Nucl Med. 1985;26:1211-1214.

8. Stabin M, Taylor A, Eshima D, Wooten W. Radiation dosimetry for technetium99m-MAG3, technetium-99m-DTPA, and iodine-131-OIH based on human biodistribution studies. J Nucl Med. 1992;33:33-40.

9. Uchino H, Tamai I, Yamashita K, et al. p-aminohippuric acid transport at renal apical membrane mediated by human inorganic phosphate transporter NPT1. Biochem Biophys Res Commun. 2000;270:254-259.

10. Taylor A, Ziffer JA, Eshima D. Comparison of Tc-99m MAG3 and Tc-99m DTPA in renal transplant patients with impaired renal function. Clin Nucl Med. 1990; 15:371-378.

11. Taylor A, Clark S, Ball T. Comparison of Tc-99m MAG3 and Tc-99m DTPA scintigraphy in neonates. Clin Nucl Med. 1994;19:575-580.

12. O'Reilly P, Aurell M, Britton K, Kletter K, Rosenthal L, Testa T. Consensus on diuresis renography for investigating the dilated upper urinary tract. Radionuclides in Nephrourology Group. Consensus Committee on Diuresis Renography. J Nucl Med. 1996;37:1872-1876.

13. Gordon I, Colarinha P, Fettich J, et al. Guidelines for standard and diuretic renography in children. Eur J Nucl Med. 2001;28:BP21-BP30.

14. Shulkin BL, Mandell GA, Cooper JA, et al. Procedure guideline for diuretic renography in children 3.0. J Nucl Med Technol. 2008;36:162-168.

15. Conway JJ, Maizels M. The "well tempered" diuretic renogram: a standard method to examine the asymptomatic neonate with hydronephrosis or hydroureteronephrosis-a report from combined meetings of the Society for Fetal Urology and members of the Pediatric Nuclear Medicine Council-The Society of Nuclear Medicine. J Nucl Med. 1992;33:2047-2051.

16. Esteves FP, Taylor A, Manatunga A, Folks RD, Krishnan M, Garcia EV. ${ }^{99 \mathrm{~m}}$ TcMAG3 renography: normal values for MAG3 clearance and curve parameters, excretory parameters, and residual urine volume. AJR. 2006;187:W610-W617.

17. Russell CD, Taylor AT, Dubovsky EV. Measurement of renal function with technetium-99m-MAG3 in children and adults. J Nucl Med. 1996;37:588-593.

18. Taylor A Jr, Eshima D, Christian PE, Wooten WW, Hansen L, McElvany K. Technetium-99m MAG3 kit formulation: preliminary results in normal volunteers and patients with renal failure. J Nucl Med. 1988;29:616-622.

19. Sanchez J, Friedman S, Kempf J, Abdel-Dayem H. Gallbladder activity appearing 6 minutes after the intravenous injection of Tc99m MAG3 simulating a picture of obstructive uropathy of the right kidney. Clin Nucl Med. 1993;18:30-34.

20. Rosen JM. Gallbladder uptake simulating hydronephrosis on Tc-99m MAG3 scintigraphy. Clin Nucl Med. 1993;18:713-714.

21. Shattuck LA, Eshima D, Taylor AT Jr, et al. Evaluation of the hepatobiliary excretion of technetium-99m-MAG3 and reconstitution factors affecting radiochemical purity. J Nucl Med. 1994;35:349-355.

22. Van Nerom CG, Bormans GM, De Roo MJ, Verbruggen AM. First experience in healthy volunteers with Tc-99m-L,L-ethylenedicysteine: a new renal imaging agent. Eur J Nucl Med. 1993;20:738-746.

23. Taylor A, Hansen L, Eshima D, et al. Comparison of technetium-99m-LL-EC isomers in rats and humans. J Nucl Med. 1997;38:821-826.

24. Taylor AT, Lipowska M, Marzilli LG. ${ }^{99 \mathrm{~m}} \mathrm{Tc}(\mathrm{CO})_{3}(\mathrm{NTA}):$ A ${ }^{99 \mathrm{~m}} \mathrm{Tc}$ renal tracer with pharmacokinetic properties comparable to those of ${ }^{131} \mathrm{I}-\mathrm{OIH}$ in healthy volunteers. J Nucl Med. 2010;51:391-396.

25. Taylor AT, Lipowska M, Cai H. ${ }^{99 \mathrm{~m}} \mathrm{Tc}(\mathrm{CO})_{3}(\mathrm{NTA})$ and ${ }^{131} \mathrm{I}-\mathrm{OIH}$ : comparable plasma clearances in patients with chronic kidney disease. J Nucl Med. 2013;54: $578-584$.
26. Piepsz A, Colarinha P, Gordon I, et al. Guidelines for ${ }^{99} \mathrm{~m}$ Tc-DMSA scintigraphy in children. Eur J Nucl Med. 2001;28:BP37-BP41.

27. Rossleigh MA. Renal infection and vesico-ureteric reflux. Semin Nucl Med. 2007;37:261-268

28. Arnold RW, Subramanian G, McAfee JG, Blair RJ, Thomas FD. Comparison of ${ }^{99 m}$ Tc complexes for renal imaging. J Nucl Med. 1975;16:357-367.

29. Szabo Z, Xia J, Mathews WB. Radiopharmaceuticals for renal positron emission tomography imaging. Semin Nucl Med. 2008;38:20-31.

30. Brough RJ, Lancashire MJ, Prince JR, et al. The effect of diclofenac (Voltarol) and pethidine on ureteric peristalsis and the isotope renogram. Eur J Nucl Med. 1998;25:1520-1523.

31. Kinn AC, Larsson SA, Nelson E, Jacobsson H. Diclofenac treatment prolongs renal transit time in acute ureteral obstruction: a renographic study. Eur Urol. 2000;37:334-338

32. Mustafa S, Elgazzar AH. Effect of the NSAID diclofenac on ${ }^{99 m}$ Tc-MAG3 and 99m Tc-DTPA renography. J Nucl Med. 2013;54:801-806.

33. Taylor A, Eshima D, Fritzberg AR, Christian PE, Kasina S. Comparison of iodine-131 OIH and technetium-99m MAG3 renal imaging in volunteers. $J$ Nucl Med. 1986;27:795-803.

34. Hilson AJW, Maisey MN, Brown CB, Ogg CS, Bewick MS. Dynamic renal transplant imaging with Tc-99m DTPA (Sn) supplemented by a transplant perfusion index in the management of renal transplants. J Nucl Med. 1978;19:994-1000.

35. Peters AM, Brown J, Crossman D, et al. Noninvasive measurement of renal blood flow with technetium-99m-DTPA in the evaluation of patients with suspected renovascular hypertension. J Nucl Med. 1990;31:1980-1985.

36. el Maghraby TA, van Eck-Smit BL, de Fijter JW, Pauwels EK. Quantitative scintigraphic parameters for the assessment of renal transplant patients. Eur J Radiol. 1998;28:256-269.

37. Prigent A, Cosgriff P, Gates GF, et al. Consensus report on quality control of quantitative measurements of renal function obtained from renogram. Semin Nucl Med. 1999;29:146-159.

38. Taylor AT, Blaufox MD, De Palma D, et al. Guidance document for structured reporting of diuresis renography. Semin Nucl Med. 2012;42:41-48.

39. Taylor A, Nally J, Aurell M, et al. Consensus report on ACE inhibitor renography for detecting renovascular hypertension. J Nucl Med. 1996;37:1876-1882.

40. Taylor AT Jr, Blaufox MD, Dubovsky EV, et al. Society of Nuclear Medicine procedure guideline for diagnosis of renovascular hypertension. Society of Nuclear Medicine and Molecular Imaging website. http://interactive.snm.org/ docs/pg_ch16_0403.pdf. Published August 2003. Accessed January 29, 2014.

41. O'Reilly PH. Upper urinary tract: standardization of the renogram technique for investigating the dilated upper urinary tract and assessing the results of surgery. BJU Int. 2003;91:239-243.

42. Taylor A, Lewis C, Giacometti A, Hall EC, Barefield KP. Improved formulas for the estimation of renal depth in adults. J Nucl Med. 1993;34:1766-1769.

43. Tartaglione G, D'Addessi A, De Waure C, et al. ${ }^{99 m}$ Tc-MAG diuretic renography in diagnosis of obstructive nephropathy in adults: a comparison between F-15 and a new procedure F+10(sp) in seated position. Clin Nucl Med. 2013;38:432-436.

44. Taylor A Jr, Thakore K, Folks R, Halkar R, Manatunga A. Background subtraction in Tc-99m-MAG3 renography. J Nucl Med. 1997;38:74-79.

45. Taylor A, Kipper MS. The qualitative I-131 hippuran renogram: a potential problem. Clin Nucl Med. 1983;8:149-154.

46. Sennewald K, Taylor A Jr. A pitfall in calculating differential renal function in patients with renal failure. Clin Nucl Med. 1993;18:377-381.

47. Taylor AT, Shenvi N, Folks RD, Garcia EV, Savir-Baruch B, Manatunga A. Reference values for renal size obtained from MAG3 scintigraphy. Clin Nucl Med. 2013;38:13-17.

48. Piepsz A, Kuyvenhoven JD, Tondeur M, Ham H. Normalized residual activity: usual values and robustness of the method. J Nucl Med. 2002;43:33-38.

49. Donoso G, Kuyvenhoven JD, Ham H, Piepsz A. ${ }^{99 m}$ Tc-MAG3 diuretic renography in children: a comparison between F0 and F + 20. Nucl Med Commun. 2003;24:1189-1193.

50. Bao J, Manatunga A, Binongo JNG, Taylor AT. Key variables for interpreting ${ }^{99 \mathrm{~m}} \mathrm{Tc}$-mercaptoacetyltriglycine diuretic scans: development and validation of a predictive model. AJR. 2011;197:325-333.

51. Piepsz A, Tondeur M, Ham H. NORA: a simple and reliable parameter for estimating renal output with or without frusemide challenge. Nucl Med Commun. 2000;21:317-323.

52. Blaufox MD, Fine EJ, Heller S, et al. Prospective study of simultaneous orthoiodohippurate and diethylenetriaminepentaacetic acid captopril renography. $\mathrm{J} \mathrm{Nucl}$ Med. 1998;39:522-528.

53. Strauss BS, Blaufox MD. Estimation of residual urine and urine flow rates without ureteral catheterization. J Nucl Med. 1970;11:81-84.

54. Levey AS, Madaio MP, Perrone RD. Laboratory assessment of renal disease: clearance, urinalysis and renal biopsy In: Brenner BM, Rector FC, eds. The Kidney. 
Philadelphia, PA: WB Saunders Company, Harcourt Brace, Jovanovich Inc.; 1991: 919-968.

55. Bröchner-Mortensen J, Rodbro P. Selection of routine method for determination of glomerular filtration rate in adult patients. Scand J Clin Lab Invest. 1976;36:35-43.

56. Levey AS, Bosch JP, Lewis JB, Greene T, Rogers N, Roth D. A more accurate method to estimate glomerular filtration rate from serum creatinine: a new prediction equation. Modification of Diet in Renal Disease Study Group. Ann Intern Med. 1999;130:461-470.

57. National Kidney Foundation. K/DOQI clinical practice guidelines for chronic kidney disease: evaluation, classification and stratification. Am J Kidney Dis. 2002;39:S1-S266.

58. Froissart M, Rossert J, Jacquot C, Paillard M, Houillier P. Predictive performance of the modification of diet in renal disease and Codkcroft-Gault equations for estimating renal function. $J$ Am Soc Nephrol. 2005;16:763-773.

59. Prigent A. Monitoring renal function and limitations of renal function tests. Semin Nucl Med. 2008;38:32-46.

60. Sapirstein LA, Vidt DG, Mandel MJ, Hanusek G. Volumes of distribution and clearances of intravenously injected creatinine in the dog. Am J Physiol. 1955;181:330-336.

61. Bubeck B. Renal clearance determination with one blood sample: improved accuracy and universal applicability by a new calculation principle. Semin Nucl Med. 1993;23:73-86.

62. Murray AW, Barnfield MC, Waller ML, Telford T, Peters AM. Assessment of glomerular filtration rate measurement with plasma sampling: a technical review. J Nucl Med Technol. 2013;41:67-75.
63. Schlegel JU, Hamway SA. Individual renal plasma flow determination in 2 minutes. J Urol. 1976;116:282-285.

64. Gates GF. Split renal function testing using Tc-99m DTPA: rapid technique for determining differential filtration. Clin Nucl Med. 1983;8:400-407.

65. Taylor A Jr, Corrigan PL, Galt J, et al. Measuring technetium-99m-MAG3 clearance with an improved camera-based method. J Nucl Med. 1995;36: 1689-1695.

66. Bocher M, Shrem Y, Tappiser A, et al. Tc-99m mercaptoacetyltriglycine clearance: comparison of camera-assisted methods. Clin Nucl Med. 2001;26: 745-750.

67. Taylor A Jr, Manatunga A, Morton K, et al. Multicenter trial validation of a camera based method to measure Tc-99m mercaptoacetyltriglycine or Tc-99m MAG3, clearance. Radiology. 1997;204:47-54.

68. Halkar R, Taylor A, Manatunga A, et al. Monitoring renal function: a prospective study comparing camera-based Tc-99m mercaptoacetyltriglycine clearance and creatinine clearance. Urology. 2007;69:426-430.

69. Tonnesen $\mathrm{KH}$, Munck O, Hald T. Influence on the radiorenogram of variation in skin to kidney distance and the clinical importance hereof. In: Zum Winkel K, Blaufox MD, Funck-Bretano JL, eds. Proceedings of the International Symposium on Radionuclides in Nephrourology 1974. Stuttgart, Germany: Thieme; 1974: 79-86.

70. Samal M, Ptacnik V, Skibova D, Jiskrova H, Kubinyi J. Simple model-based method for gamma-camera measurement of 99m-MAG3 plasma clearance [abstract]. J Nucl Med. 2013;54(suppl):170P-171P. 